\title{
Thermal tools to evaluation of decayed and weathered wood polymer composites prepared by in situ polymerization
}

\author{
Bruno Mattos ${ }^{1}$; Marcelo Lazzarotto ${ }^{2}$; Washington Luiz Esteves Magalhães ${ }^{2}$; Darci Alberto Gatto ${ }^{3}$ \\ ${ }^{1}$ Integrate program in Engineering \& Materials Science (PIPE), Federal University of Paraná, Polytechnic Centre, P.O. Box \\ 19011, ZIP code 81531-990, Curitiba, PR, Brazil. \\ ${ }^{2}$ Embrapa Forests, P.O.Box 319, ZIP code 83411-000, Colombo, PR, Brazil. \\ ${ }^{3}$ Development Centre of Technology, Federal University of Pelotas, Félix da Cunha 809, ZIP code 96010-000, Pelotas, RS, \\ Brazil
}

\begin{abstract}
This study aims to apply thermal tools in the evaluation of decayed and weathered wood polymer composites prepared by in situ polymerization of methyl methacrylate (MMA) using glycidyl methacrylate (GMA) and methacrylic acid (MAA) as cross-linkers. The pine wood samples were impregnated in a vacuum/pressure system and polymerized in an oven at $90^{\circ} \mathrm{C}$ for $10 \mathrm{~h}$, using benzoyl peroxide at $1.5 \mathrm{wt} \%$ as catalyst. The untreated wood and composites were exposed to in vitro decay tests with Trametes versicolor and Gloeophyllum trabeum fungi, and to artificial weathering. The weight loss after tests was measured, and the characterization was performed by thermogravimetric (TGA) and differential scanning calorimetry (DSC) analysis. The mass loss caused by exposure to fungi was evidently higher in untreated wood in relation to the composites, $\sim 2.5$ to 10 times - the composites with GMA and MAA showed the highest resistance to both fungi. The composites without cross-linkers showed the higher mass loss in the artificial weathering tests $(>11 \%)$, due to the leaching of part of poly(MMA) formed inside wood. By TGA and DSC analysis, we observed shifting in the temperature of thermal events related to polysaccharides and lignin after exposed to decays tests - more significant changes were for Trametes versicolor tests. The thermograms related to weathered samples showed different results for each composite. The untreated wood and the composite without cross-linker presented loss in lignin, meanwhile the composites with cross-linkers presented degradation in the copolymer formed onto surface of wood.
\end{abstract}

Keywords: TGA, DSC, pinewood, methacrylate, additives

\section{Introduction}

Natural biodegradable materials are widely used in civil engineering constructions, and are exposed to deterioration processes due to chemical, environmental or microbial origins. The rate of material deterioration is directly dependent on the environment to which the material will be exposed. Among biodegradable materials, wood is considered durable in relation to the ability to preserve its structural properties under weathering, but not for the attack of xylophage organisms [1].

The wood constitution is formed by flexible cellulose fibers assembled in an amorphous matrix of lignin with hemicellulosic polymer, and further form special natural cellular structure with high strength-to-weight ratio. Among the main inherent characteristics of wood, hygroscopicity is the most restrictive property. The wood capacity for water sorption from its surroundings leads to a series of interconnected technological problems, which are limiting. Problems related to increased wood moisture include dimensional swelling, variation of density, and mainly increased susceptibility to biodeterioration [2]. All these issues may result in irreversible damage to wood structures.

To increase applications of wood, several treatments are widely applied, such as the preparation of wood polymer composites by in situ polymerization [3-5]. For the production of wood polymer composites, solid wood is impregnated by unsaturated monomers followed by in situ polymerization [6-9]. This method uses the microstructurally organized wood as a template, and the in situ synthesized polymer is the reinforcement, resulting in new materials with physical, biological and mechanical properties better than untreated wood $[6,4]$.

To evaluate these wood composites, many tools are used, including water uptake tests, infrared spectroscopy, dimensional stability tests, electron microscopy, mechanical tests, and so on [6,7]. In addition, the thermal tools like as thermogravimetric and differential scanning calorimetry analysis, can be useful.

In general, the thermal techniques were widely applied to evaluation of thermal behavior of wood and wood products [10,11], and also for evaluation of lignocellulosic biomass combustion kinetics [12] and fuels from wood residues [13]., the thermogravimetric analysis was applied to quantify the percentage of polypropylene in wood polymer composites [14]. Many others researches has used the thermal tools to evaluating of grafting reactions [15], in situ polymerizations [6], thermal treatments [16], and biodeterioration of woods [1] - showing the wide range of applicability of these thermal techniques.

This study aims to apply the thermal tools in the evaluation of decayed and weathered wood polymer composites prepared by in situ polymerization of methyl methacrylate (MMA) using glycidyl methacrylate (GMA) and methacrylic acid (MAA) as cross-linkers. 


\section{Materials and Methods}

\section{Materials}

A local sawmill (Madarco-S.A.) provided Pinus taeda wood. Fifteen pinewood samples were prepared from defect free wood, cut into blocks of $1.5 \times 1.5 \times 2.5 \mathrm{~cm}^{3}$ (thickness, width and length, respectively). The methyl methacrylate (MMA), glycidyl methacrylate (GMA) and methacrylic acid (MAA) purchased from Sigma Aldrich were used as received. Benzoyl peroxide (BPO) obtained from Vetec Química Fina (Brazil) was used as the free radical catalyst activated by heat.

\section{Preparation of the wood-polymer composites}

The samples were oven-dried at $90 \pm 2^{\circ} \mathrm{C}$, until constant weight ( $\sim 2$ days) and then cooled in a silica gel desiccator. The monomeric solutions were prepared according to Table 1 and $1.5 \mathrm{wt} . \%$ of benzoyl peroxide was added.

Table 1. Specification of the pine wood/polymer composites.

\begin{tabular}{ccccc}
\hline \multirow{2}{*}{$\begin{array}{c}\text { Code } \\
\text { treatment }\end{array}$} & \multicolumn{3}{c}{$\%$} & $\mathrm{wt} \%$ \\
\cline { 2 - 5 } W (Control) & MMA & GMA & MAA & BPO \\
W/M & 100 & - & - & - \\
W/M:G $(2: 1)$ & 66.5 & 33.5 & - & 1.5 \\
W/M:A (2:1) & 66.5 & - & 33.5 & 1.5 \\
\hline
\end{tabular}

The samples vacuumed at $600 \mathrm{mmHg}$ during 30 minutes using a stainless cylinder. After that, the solution was released into the cylinder followed by pressurization by compressed air at 6 atm for $1 \mathrm{~h}$. After impregnation, the excess chemicals were removed from the surfaces. Then, the samples were wrapped in aluminum foils and polymerized at $90 \pm 2^{\circ} \mathrm{C}$ for $10 \mathrm{~h}$.

\section{Weight percent gain (WPG)}

Weight percent gain (WPG) after polymer loading was calculated according to equation 1, as previously mentioned in other studies $[4,17,18]$.

$$
\mathrm{WPG}=[(\mathrm{Wp}-\mathrm{W} 0) / \mathrm{W} 0] * 100
$$

where: $\mathrm{Wp}=$ weight of sample after the treatment; $\mathrm{W} 0=$ weight of sample before the treatment.

\section{In vitro decay tests}

The in vitro decay resistance tests were performed according to EN Standard (PN-EN113). Brown decay fungi (Gloeophyllum trabeum (Pers. ex Fr.) Murr.) and white decay fungi (Trametes versicolor (Linnaes ex Fr.) Pilat.) were used and the untreated pinewood and the three wood polymer composites (five replicates for each treatment) were exposed to decay for sixteen weeks.

\section{Artificial weathering tests}

The untreated and wood polymer composites samples were exposed to an artificial weathering using a $340 \mathrm{~nm}$ fluorescent UV lamps in a Bass equipment. We performed 120 cycles, totaling $1440 \mathrm{~h}$ of exposure. Each weathering cycle involved a continuous UVA light irradiation of $8 \mathrm{~h}$ at $60 \pm 3^{\circ} \mathrm{C}, 0.25 \mathrm{~h}$ of water spray (no light), and $3.75 \mathrm{~h}$ of condensation at $50 \pm 3^{\circ} \mathrm{C}$, according to the Cycle 7 of the ASTM G154 (2000).

\section{Thermogravimetric analysis (TGA)}

The thermogravimetric curves were obtained in a DTG-60 equipment from Shimadzu, using an inert atmosphere with nitrogen gas flow of $20 \mathrm{ml} \cdot \mathrm{min}^{-1}$, temperature range between 25 and $600^{\circ} \mathrm{C}$, and heating rate of $10^{\circ} \mathrm{C} . \mathrm{min}-1$. The weight of the samples ranged from $5-8 \mathrm{mg}$ inside a platinum pan for allocating the samples in the device.

\section{Differential scanning calorimetry analysis (DSC)}

DSC thermograms were obtained from $\sim 5 \mathrm{mg}$ of sample into an aluminum pan immersed in an inert nitrogen atmosphere (gas flow of $20 \mathrm{ml} \cdot \mathrm{min}^{-1}$ ) at a heating rate of $10^{\circ} \mathrm{C} \cdot \mathrm{min}^{-1}$. Samples were heated from room temperature to $600^{\circ} \mathrm{C}$ on $\mathrm{Shimadzu}$ DSC-60 equipment. 


\section{Results and Discussion}

\section{Weight percent results}

The expected crosslinking reactions between the copolymers, after insertion of GMA and MAA, and the wood cell wall are via epoxy ring and - $\mathrm{COOH}$ with free $\mathrm{OH}$ groups, respectively. The lowest weight percent gain obtained for the composite W/M (39.4\%) contrasts with the highest for the W/M:G 2:1 (64.7\%), showing statistically significant difference between the treatments (Table 2).

Table 2. Summary of ANOVA one-way for the WPG of pine wood/polymer composites.

\begin{tabular}{cccc}
\hline W/M & W/M:G 2:1 & W/M:A 2:1 & F-ratio \\
\cline { 1 - 3 } $39.4 \pm 10.1$ a & $64.7 \pm 9.01$ d & $50.6 \pm 9.1$ bc & $10.95 *$ \\
\hline \multicolumn{4}{c}{ * Significant at 1\% of probability error }
\end{tabular}

Generally, WPG increases with after the insertion of cross-linkers, as previously reported by other authors [19,20]. In general, the cross-linkers - more polar substances as GMA and MAA - are also coupling agents between the reinforcement (copolymers) and wood cell wall, and this explains the increment of WPG.

\section{Decay and weathering results}

The weight loss for untreated pinewood after decay was $\sim 2,5$ and 5 times higher than for W/M composite after exposure to Trametes versicolor and Gloeophyllum trabeum (Table 3), respectively. However, after the addition of GMA and MAA, the decay resistance was more than $\sim 5$ and 10 times, for white and brown fungi rots, respectively. Therefore, GMA treatment significantly decreased the susceptibility of pinewood to rot fungi. The main reasons are the chemical modification of the wood $\mathrm{OH}$ that block enzymatic hydrolysis and oxidative degradation $[5,18]$, and cause the moisture exclusion [2].

Table 3. Weight loss of samples after decay and weathering tests

\begin{tabular}{cccc}
\hline \multirow{2}{*}{ Sample } & \multicolumn{2}{c}{ Decayed } & \\
\cline { 2 - 3 } & $\begin{array}{c}\text { Trametes } \\
\text { versicolor }\end{array}$ & $\begin{array}{c}\text { Gloeophyllum } \\
\text { trabeum }\end{array}$ & Weathered \\
\hline Control & $17.4 \pm 4.33$ & $10.1 \pm 3.25$ & $4.54 \pm 0.54$ \\
W/M & $7.3 \pm 1,61$ & $2.1 \pm 0.93$ & $11.4 \pm 0.49$ \\
W/M:G 2:1 & $3.6 \pm 0,63$ & $1.7 \pm 0.70$ & $2.7 \pm 1.39$ \\
W/M:A 2:1 & $2.3 \pm 1,69$ & $1.3 \pm 0.89$ & $4.6 \pm 1.02$ \\
\hline
\end{tabular}

The weight loss observed for the samples after weathering occurred mainly by leaching of wood fibers after oxidation of the lignin present in the external surface of the sample [21], unleashing a slow, but cyclical, process of degradation. On the other hand, the W/M composite, without cross-linkers, has layers of polymer not chemically bonded to the surface of the wood, which end up being photodegraded and easily leached. This excess of polymer leaching resulted in a highest weight loss $(>11 \%)$. The composites with cross-linkers showed lower weight loss when compared with W/M composite - this result occurs due to the high compatibility between de copolymer and wood, avoiding the lixiviation of chemicals.

\section{Thermal and calorimetry study of decayed and weathered wood polymer composite}

To compare the results of decayed and weathered of untreated and composite samples (Figure 2 and 3 ) we added TG and DSC thermograms of the poly (MMA), poly (GMA) and poly (MAA) (Figure 1). Peaks at 288 and $371{ }^{\circ} \mathrm{C}$ correspond to the two main thermal decompositions of the poly (MMA). In addition, there is an intense peak at $428^{\circ} \mathrm{C}$ for the thermal decomposition of the poly (MAA). The thermal decomposition of poly (GMA) shows the main peak at $279^{\circ} \mathrm{C}$, while the second higher rate of mass loss was observed around $421^{\circ} \mathrm{C}$.

DSC thermograms (Figure 1, at right) shown different thermodynamic events of the polymers used here. The exothermic peaks at $\sim 260^{\circ} \mathrm{C}, 280^{\circ} \mathrm{C}$ and $400^{\circ} \mathrm{C}$ are related to thermal decomposition of the poly (GMA), poly (MMA), and poly (MAA), respectively. We noted that the thermal events appear at different temperatures for different polymers, but essentially, the behavior is quite similar.

In the thermograms of untreated wood, we verified two main thermal events (Figure 2). The first, with onset at $280^{\circ} \mathrm{C}$ and endset at $360^{\circ} \mathrm{C}$ is related to thermal decomposition of hemicellulose and amorphous and crystalline cellulose [22]. The second peak corresponding to thermal degradation of lignin with maximum peak at $\sim 480^{\circ} \mathrm{C}$, however we pointed that the lignin degrades since mild temperatures $\left(<100^{\circ} \mathrm{C}\right)$ at a very slow rate [23]. 

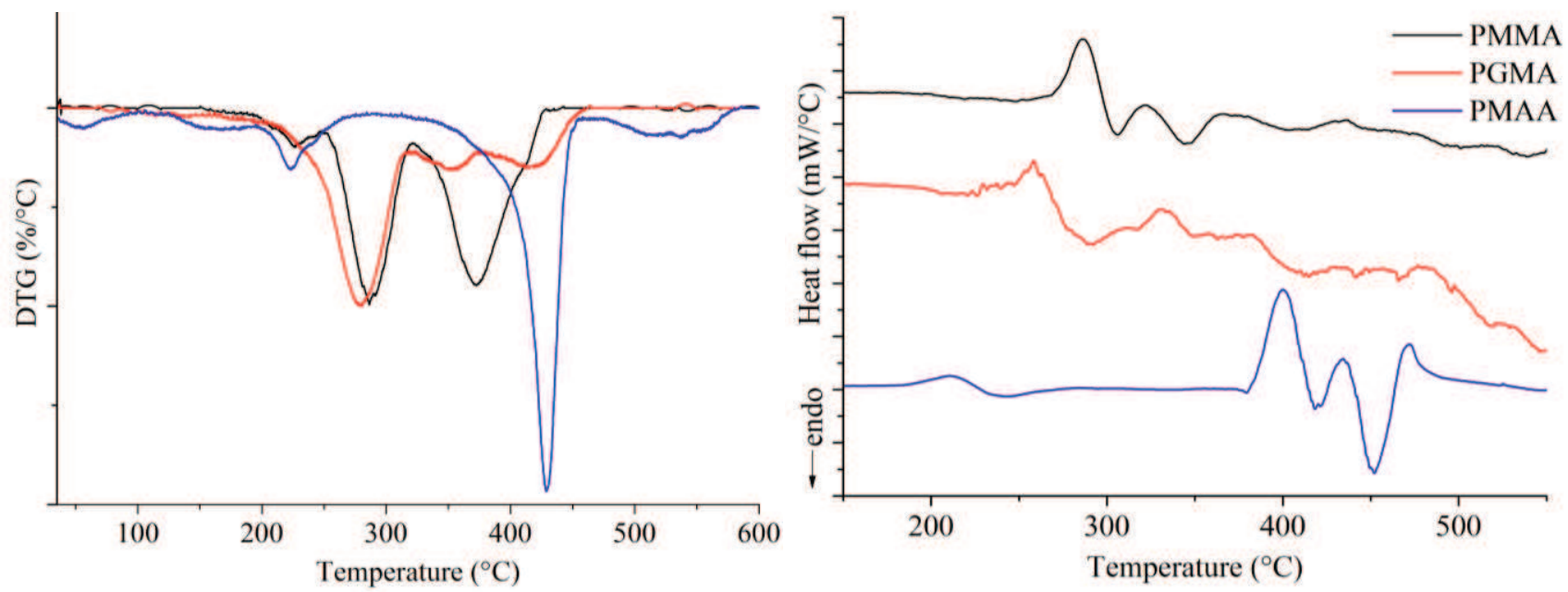

Figure 1. First derivative of TG and DSC curves of polymers used in the in situ polymerization

The untreated decayed samples, for both fungi, presented changes in the stage corresponding to carbohydrates of wood, meanwhile the weathered samples showed changes in main stage of lignin decomposition. The composite W/M showed similarities between the curves of the control, decayed and weathered samples, however, the difference observed above $400^{\circ} \mathrm{C}$ shows that fungi degrade only the woods. W/M composite showed very degradation at $400^{\circ} \mathrm{C}$ after artificial weathering tests, which shows that the lignin was oxidized in the surface and the poly (MMA) was photodegraded and leached.
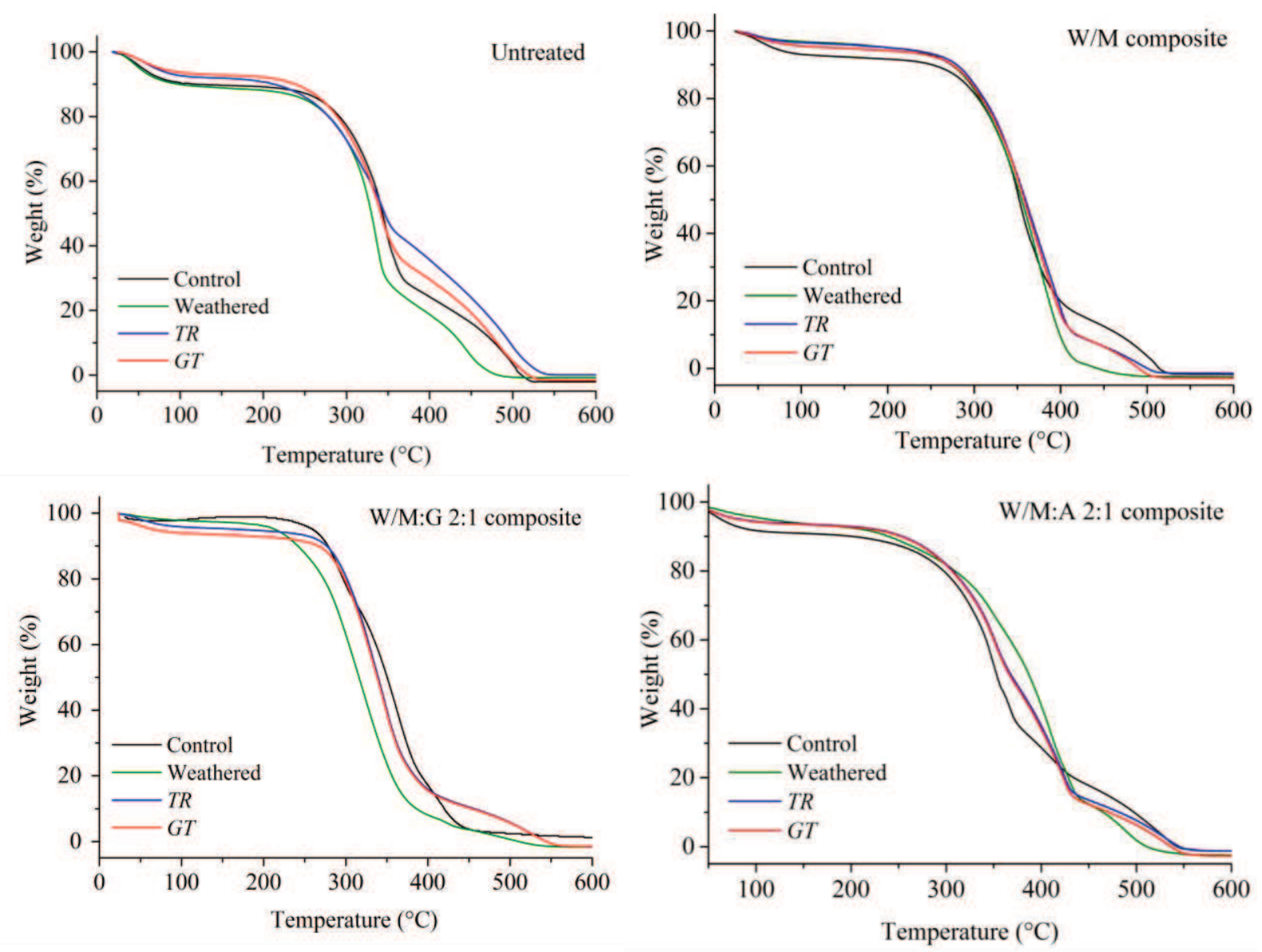

Figure 2. Thermogravimetric curves of pinewood and wood polymer composites after weathering and decay tests. 
The W/M:G 2:1 and W/M:A 2:1 composites showed slight changes in the TG curves after weathering and decay tests, corroborating with weigh loss measures. The main changes are observed in the weathered samples, with the main thermal decomposition at lower temperatures for the W/M:G 2:1, and at higher temperatures for the W/M:A 2:1, when compared with respectively controls samples. Was observed in the weathered surface of these composite samples had more polymer than wood. For composites with cross-linkers, both fungi have cause very low changes, as previously reported (Table 2). Li et al. [5] showed very similar results to those observed here, especially in the subsequent decrease in the weight loss in the decay tests after adding small loads of GMA as cross-linker.

The DSC thermogram of the untreated wood showed an slightly exothermic peak at $360^{\circ} \mathrm{C}$ ascribed to thermal decomposition of the wood fibres, as previously verified by Devi, Maji [24]. However, the composite W/M showed two distinct exothermic peaks, one of which relates to the decomposition of the wood fibres $\left(360^{\circ} \mathrm{C}\right)$ and the other relates to the poly (MMA) $\left(422^{\circ} \mathrm{C}\right)$. For untreated weathered samples, we observed an increase in the peak at $360^{\circ} \mathrm{C}$, mainly to increase of the carbohydrates by degradation of lignin after weathering tests. On the other hand, for W/M composite we observed that the event of decomposition was at higher temperatures, which implies a higher proportion of polymer when compared with wood. Decayed samples, for both untreated and W/M, presented similar behaviour of the respectively controls.
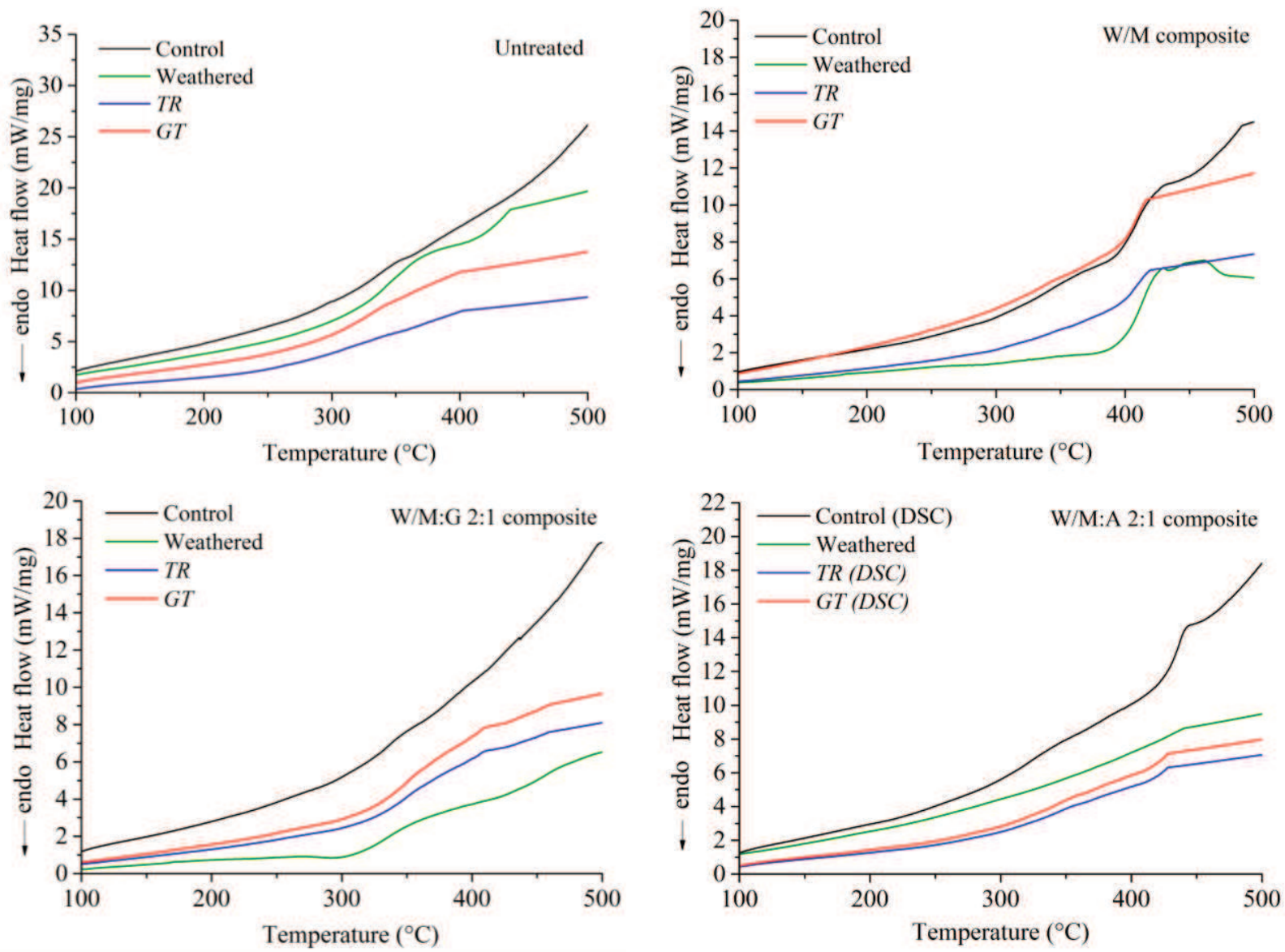

Figure 3. DSC curves of pinewood and wood polymer composites after weathering and decay tests.

The DSC curve of weathered W/M:G 2:1 sample showed an event at $\sim 280-300^{\circ} \mathrm{C}$ due the degradation of poly(GMA), as previously reported in TG curve. The peak at this temperature confirms the surface contains mainly polymer after weathering tests. DSC curves of W/M:A 2:1 presented similar behavior, however with lower heat flow when compared with control samples.

\section{Conclusions}

The decaying and weathering are higher for untreated wood, followed by W/M composite. The composites with crosslinker presented very low degradation.

The best thermal tool to evaluation these degradation phenomena was the TGA technique, because the events of thermal decomposition are not clear in the DSC thermograms. 


\section{References}

1. Mattos BD, de Cademartori PHG, Lourençon TV, Gatto DA, Magalhães WLE. Biodeterioration of wood from two fastgrowing eucalypts exposed to field test. International Biodeterioration \& Biodegradation. 2014;93(0):210-5.

2. Thybring EE. The decay resistance of modified wood influenced by moisture exclusion and swelling reduction. International Biodeterioration \& Biodegradation. 2013;82(0):87-95.

3. Devi R, Maji T. Effect of nanofillers on flame retardancy, chemical resistance, antibacterial properties and biodegradation of wood/styrene acrylonitrile co-polymer composites. Wood Sci Technol. 2013;47(6):1135-52.

4. Islam MS, Hamdan S, Hassan A, Talib ZA, Sobuz H. The chemical modification of tropical wood polymer composites. Journal of Composite Materials. 2013.

5. Li Y, Dong X, Liu Y, Li J, Wang F. Improvement of decay resistance of wood via combination treatment on wood cell wall: Swell-bonding with maleic anhydride and graft copolymerization with glycidyl methacrylate and methyl methacrylate. International Biodeterioration \& Biodegradation. 2011;65(7):1087-94.

6. Devi RR, Maji TK. In situ polymerized wood polymer composite: effect of additives and nanoclay on the thermal, mechanical properties. Materials Research. 2013;16:954-63.

7. Ding W-D, Koubaa A, Chaala A. Mechanical properties of MMA-hardened hybrid poplar wood. Industrial Crops and Products. 2013;46(0):304-10. 8. Ding W-D, Koubaa A, Chaala A, Belem T, Krause C. Relationship between wood porosity, wood density and methyl methacrylate impregnation rate. Wood Material Science \& Engineering. 2008;3(1-2):62-70.

9. Hadi YS, Rahayu IS, Danu S. Physical and mechanical properties of methyl methacrylate impregnated jabon wood. J Indian Acad Wood Sci. 2013:1-4.

10. Fang Y, Wang Q, Bai X, Wang W, Cooper P. Thermal and burning properties of wood flour-poly(vinyl chloride) composite. J Therm Anal Calorim. 2012;109(3):1577-85.

11. Sebio-Puñal T, Naya S, López-Beceiro J, Tarrío-Saavedra J, Artiaga R. Thermogravimetric analysis of wood, holocellulose, and lignin from five wood species. J Therm Anal Calorim. 2012;109(3):1163-7.

12. Cheng K, Winter WT, Stipanovic AJ. A modulated-TGA approach to the kinetics of lignocellulosic biomass pyrolysis/combustion. Polymer Degradation and Stability. 2012;97(9):1606-15.

13. Skreiberg A, Skreiberg $\varnothing$, Sandquist J, Sørum L. TGA and macro-TGA characterisation of biomass fuels and fuel mixtures. Fuel. 2011;90(6):2182-97.

14. Jeske H, Schirp A, Cornelius F. Development of a thermogravimetric analysis (TGA) method for quantitative analysis of wood flour and polypropylene in wood plastic composites (WPC). Thermochimica Acta. 2012;543(0):165-71.

15. Martini R, Serrano L, Barbosa S, Labidi J. Antifungal cellulose by capsaicin grafting. Cellulose. 2014:1-11.

16. Cademartori PHG, dos Santos PSB, Serrano L, Labidi J, Gatto DA. Effect of thermal treatment on physicochemical properties of Gympie messmate wood. Industrial Crops and Products. 2013;45(0):360-6.

17. Hazarika A, Maji TK. Effect of different crosslinkers on properties of melamine formaldehyde-furfuryl alcohol copolymer/montmorillonite impregnated softwood (Ficus hispida). Polymer Engineering \& Science. 2013;53(7):1394-404.

18. Li Y, Liu Z, Dong X, Fu Y, Liu Y. Comparison of decay resistance of wood and wood-polymer composite prepared by in-situ polymerization of monomers. International Biodeterioration \& Biodegradation. 2013;84(0):401-6.

19. Islam MS, Hamdan S, Jusoh I, Rahman MR, Talib ZA. Dimensional Stability and Dynamic Young's Modulus of Tropical Light Hardwood Chemically Treated with Methyl Methacrylate in Combination with Hexamethylene Diisocyanate CrossLinker. Industrial \& Engineering Chemistry Research. 2011;50(7):3900-6.

20. Li Y, Wu Q, Li J, Liu Y, Wang X-M, Liu Z. Improvement of dimensional stability of wood via combination treatment: swelling with maleic anhydride and grafting with glycidyl methacrylate and methyl methacrylate. Holzforschung 2012. p. 59.

21. Feist WC, Hon DNS. Chemistry of weathering and protection. In: Rowell RM, editor. The chemistry of solid wood, advances in chemistry. Washington: American Chemical Society; 1984. p. 401-51.

22. Poletto M, Zattera AJ, Forte MMC, Santana RMC. Thermal decomposition of wood: Influence of wood components and cellulose crystallite size. Bioresource Technology. 2012;109(0):148-53..

23. Yang H, Yan R, Chen H, Lee DH, Zheng C. Characteristics of hemicellulose, cellulose and lignin pyrolysis. Fuel. 2007;86(12-13):1781-8.

24. Devi RR, Maji TK. Effect of glycidyl methacrylate on the physical properties of wood-polymer composites. Polymer Composites. 2007;28(1):1-5. 